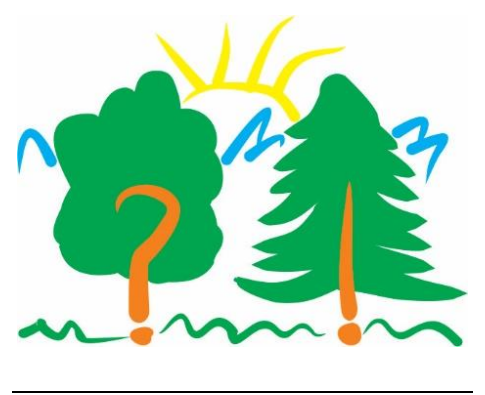

EDITORIAL NOTE

Ivetić V (2018) Reforestation

challenges 2018. Reforesta 5: 1-3.

DOI:

http://dx.doi.org/10.21750/REF OR.5.01.47

CrossMark

\section{REFORESTATION CHALLENGES 2018}

\author{
Vladan Ivetić \\ University of Belgrade - Faculty of Forestry, Belgrade, Serbia \\ vladan.ivetic@sfb.bg.ac.rs
}

The conference on "Reforestation Challenges" took place on 20-22 June 2018 in Belgrade, Serbia, at Faculty of Forestry of the University of Belgrade. This was the fourth meeting on reforestation challenges, after three successful meetings in three previous years (2015 - Belgrade, Serbia; 2016 - Krakow, Poland; 2017 - Session at the IUFRO Congress in Freiburg, Germany). This Conference, like the first one, was organized by Faculty of Forestry of the University of Belgrade, IUFRO (specifically by IUFRO Unit: 3.02.00 - Stand Establishment and Treatment), and Reforesta Scientific and professional Society.

A total of 54 participants representing 22 countries attended this Conference and used the opportunity to gather and present results and relate experiences from research areas relevant to reforestation (Figure 1).

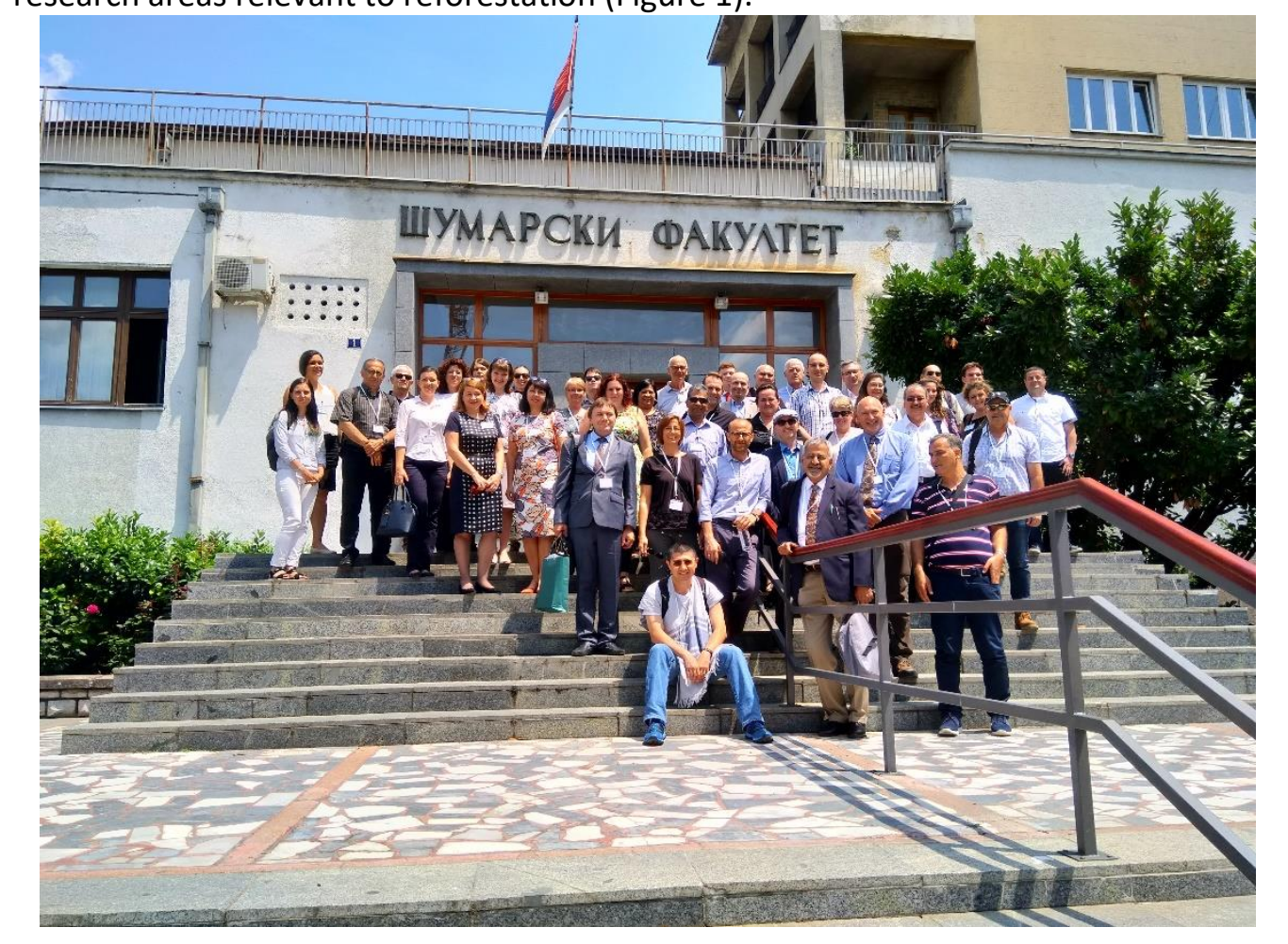

Figure 1. Reforestation Challenges, Belgrade 2018 - Group picture.

Copyright: (C) 2016 Ivetić Vladan. This work is licensed under a Creative Commons Attribution 4.0 International Public License.

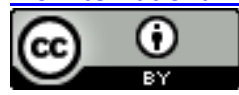


Conference was divided at following sessions:

1. Planning and management of reforestation programs

2. Stocktypes and seedling quality

3. Monitoring reforestation successes

4. Planting and seedling-site interaction

5. Species, intra-species and seed source selection

6. Plant health in nurseries and plantations

The moderators of sections voted for the best presentations. The Award for the best oral presentation belongs to Santa Neimane, from Latvia, and the Award for the best poster presentation belongs to Nelly Aggangan, from Philippines.

\section{Conference Conclusions}

Reforestation faces many challenges. Uncertainty of environmental changes reinforces the significance of a Target Plant Concept and its utility in restoring critical functions within forest landscapes. Because forestry should serve the public, foresters should focus on restoring ecosystem functions and services, rather than attempting to restore the forest structure to some historical reference. Only high-quality seedlings outplanted at the right place and at the right time will build the resilient and sustainable forests in the changing future. Some the tree species will not be able to keep up with the pace of changing climate, and assisted migration will become a standard tool in many reforestation programs. The issue of intentional movement of trees (seeds, seedlings, genes) can be restricted by different national legislation. In search for the species, provenances, and genotypes which are the best match for a focal site, foresters will often need to look across the borders, and these borders need to be relaxed in cases of transfer of forest reproductive material.

The high quality forest reproductive material, from seed to seedlings, is essential for reforestation success. Appropriate seed source selection, seed collection, and processing, are vital for establishing of new planted forests, resilient to rapid changes. With ambitious reforestation and forest restoration projects on a global scale, the real challenge is to produce enough forest reproductive material of good quality.

Only the best nursery practices will result with high quality seedlings. Yet, the significance of nursery production is often neglected, despite the numerous evidences on effect of nursery cultural practices on seedlings quality, and by that on their survival and growth after field planting. We should put more effort on recognition of significance of nursery good practices in success of reforestation. The Conference participants used the opportunity to exchange their experiences in seedling production, which is one of the most valuable result of this meeting.

Many high-tech tools are available for production of forest reproductive material, and we should look to leverage those tools to produce high-tech seedlings capable of successfully facing new challenges. In addition to genetic engineering, the less expensive nursery techniques, such as the use of LED lights and chemical root pruning, can be used to produce the New Generation Seedlings. These seedlings, with promote adaptability of root growth, will have a crucial role in building a new, resilient forests at the single tree, stand, and landscape levels.

Once outplanted, seedling will face site conditions, and the final outcome depends on a combination of seedling quality and the level of environmental stresses. 
The most critical period is the establishment phase, when seedlings begin to couple with the reforestation site by root growth into the surrounding soil. A good knowledge and understanding of ecophysiology is of a crucial importance for reforestation success.

We can help seedlings survive and grow at the outplanting site using different tools. Inoculation with mycorrhiza spores in nursery or at the planting site promotes seedling survival and subsequent growth. Vegetation control and protection from grazing are essential at many sites. The early recognizing of symptoms of diseases and pests provides an opportunity to react and to protect the seedlings. An understanding of pest (viruses, bacteria, fungi, and insects) biology is required for proper planning of reforestation programs, as well as for choosing the appropriate silvicultural practices.

Once established, planted forests need proper management. Plantation silviculture faces a myriad of spatial, production and profitability, and social issues, squeezed between forestry goals and public expectations, and limited by natural conditions and availability of resources. In addition, changing environments brings new challenges to the traditional silvicultural approaches. Some techniques of site preparation and vegetation control will require modifications, and more attention should be focused on species phenology in these changing environments.

But, what happens when we fail? The failures of reforestation programs are usually followed by loss of support for the future programs and a negative image of forestry by the public. Often, foresters are to blame, without any evidence to support such claims. In order to better understand what went wrong so as to learn from our failures, we need to develop a set of procedures ("Seedlings Forensics" and "Planting Site Investigations") to collect evidence to ascertain the reasons for failure. Results of such investigations should be the component on any report on reforestation success or failure.

We need to use all tools available in order to increase the success rate, e.g. the best practice of planting site preparation, planting techniques, and post-planting protection. Many of these methods are tested and proven at the operational level. Yet, there is a need for new techniques and methods in uncertain global change, which open opportunities for new research and inventions. We also need to emphasize the role of afforestation/reforestation in mitigating climate change by the reduction of carbon form the atmosphere. After all, the role of foresters in process of changes is positive.

\section{Conference results}

The book of abstracts was published prior the conference. A total of 61 abstracts with 146 authors from 25 countries was accepted.

All submitted full length papers from this Conference, which pass the regular editorial and peer review process, will be published in a special issued of Reforesta Journal (http://journal.reforestationchallenges.org/index.php/REFOR) in December 2018 issue.

\section{Related publications /websites:}

Ivetić V, Devetaković J (eds.) Book of abstracts: International conference Reforestation Challenges, 20-22 June 2018, Belgrade, Serbia. pp. 80. ISBN 978-86-918861-2-7

Conference website: http://www.reforestationchallenges.org/ 